Proceedings of the Seminar on the Social and Economic Effects of Earthquake Prediction, 12 October, 1977.

\title{
ROLE OF THE MEDIA IN EARTHQUAKE PREDICTION
}

\author{
M. Robson*
}

An appropriate starting point for this paper may be to examine two competing theories which cover general attitudes towards the media.

On the one hand there is the school of thought which believes that the best course in every situation is to disclose everything in the words of President Nixon's advisor John Dean during a crucial early stage in the Watergate scandal - to "let it all hang out".

On the other hand, there is the school of thought that believes the less the media is told the better and probably the best course of all is to tell the media nothing.

Let me expand on these two options. Most media people would subscribe to the first option. This philosophy argues that the media is less likely to get things wrong when it is working with all the available information. It also contends that the media is responsible and that partial disclosure of facts more often leads to confusion and misunderstanding than open and frank disclosure.

Any well-trained journalist will not be deterred by closed doors or reluctance on the part of the authorities to provide information. This is especially so when the journalist has reason to believe that there is something to hide. At this point the journalist will go to unofficial sources and while every effort will be made to check the validity of this information, it is obvious that dangers of inaccuracy are considerably increased.

The second school of thought holds that the media is basically not to be trusted. Included in this school are thosewho feel that the Press is only interested in selling newspapers and therefore will sensationalise any story to this end or, alternatively, that all reporters and editors have Machievalian motives and will distort any story to promote right or left-wing political philosophies. There are others who think the problem is that most people in the media are stupid and incompetent and cannot be expected to get anything right.

What the media are not told, says this school of thought, it cannot sensationalise, twist to its own ends or get wrong.

of course both these philosophies represent the extremes but it is as well to keep them in mind as we consider the role the media can play in the future earthquake prediction.

There is little doubt that the media will act as the conduit for information on

* Editor, "Evening Post" earthquake prediction to the general public. How that conduit is used will be crucial in shaping the attitudes of the public toward prediction and, of course, those attitudes will determine the actions of a majority of people both before, during and after a major earthquake.

The difficulty in formulating any poljcy relating to the media and earthquake prediction revolves around the fact that this is a completely new field. The number of articles that have appeared in newspapers on the subject in New Zealand could be counted on one hand and the same would apply to programmes on the topic on television and radio.

For this reason it is difficult to judge the response of either the general public or the media in handling material.

I have tried to detail, below, a practical picture of likely responses from both the media and the public - first on a long-term basis, then on the medium-term basis and finally on a short-term basis. At the same time I have suggested some of the steps which can be taken by those dispensing this information to meet certain goals.

\section{LONG-TERM}

The long-term consideration of the problem of earthquake prediction and the media is probably the most important question before this seminar, because it is the reality we are dealing with at the present time.

The prime difficulty, as I see it, is to engage the public's attention without being unnecessarily alarmist.

The responsible and attractive option, at first thought, is to begin with a low key presentation and then gradually increase the tempo of publicity.

My own view is that this would not be the best approach.

Instead, I think it is probably necessary to begin the campaign with some dramatic shock tactics.

This initial campaign should concentrate on television and radio.

The television campaign could be based around a documentary presentation. This would necessitate interesting some specific current affairs programne - probably "Prime Time" or "Seven Days" or "Perspective" into looking at the problem. Another approach, seldom used in New Zealand but common in the United States, is to obtain 
sponsorship of a specific section of time on television. This time is then used to screen a specific programme - in this case one which considers the dangers of earthquakes and the possibilities of earthquake prediction. A possible sponsor in New Zealand would be the Government. If the programme is to make an impact it must be dramatic and, as such, will probably have to be somewhat more alarmist, than sober, scientific judgement would feel justified.

Such a programme would, in its own right, attract Press interest. The programme should, however, be backed up with a concerted effort to interest the daily newspapers in printing both interpretative articles and also with some judicious advertising in advance and saturation advertising the day before the documentary is screened.

A beginning such as this should arouse public interest and firmly establish earthquake prediction as a "worthy" news event in the eyes of the people who control the flow of news in newspapers and on television and radio.

Having established earthquake prediction as a newsworthy topic it will then be the responsibility of the scientists in this field to make sure that this advantage is not lost. Calculated use of press releases should be made on a regular basis. Obviously the best time for these releases will be around the time of minor earthquakes.

It is notable in examining files on earthquakes in "The Evening Post" Iibrary that the greatest activity on the part of the newspaper in discussing earthquakes occurs at the time of more than usually strong tremors. Thus, at the time of the Inangahua quake in 1968 and a subsequent tremor later in the year that was felt very strongly in Wellington City, many column centimetres were displayed not only on these news events, but on the phenomenon of earthquakes and even on the progress being made in earthquake prediction.

These moves in the long term should concentrate firstly on establishing earthquake prediction as a viable proposition. It should be borne in mind that this is virgin territory not only for the general public but for most editors and newsmen. Unless the steps in earthquake prediction are carefully and clearly explained in this initial period, misconceptions will plague the programme from this point on.

It is my opinion that every effort must be made to eliminate red herrings and extraneous discussion at this stage. If, for instance, complicated philosophical and sociological arguments are introduced in the initial stages of discussions there is a great danger that not only will the general public dismiss the matter as too complicated and boring but that news organisations will come to the same conclusion with the result that placement of news items and articles will become that much more difficult.

It will also be important to make sure that this initial publicity is firmly orientated toward New Zealand conditions. While "exotica" has its place in determining news values it is a well known fact that readers of newspapers respond far more readily to local than overseas news. MoNair Surveys for the "Post" consistently showed that when questioned as to any feature or area of the newspapers they would like to see increased, reader response shows an overwhelming preference for more local news.

As far as I could determine in my research for this paper, most of the studies on earthquake prediction have been confined to the United States. This means that theoretical models are based on American society where both institutions and attitudes vary markedly from New Zealand.

It is my firm conviction that every effort must be made to avold the introduction of this American experience into the formulating of New Zealand answers $\cdots$ at least as far as communicating with the New Zealand public is concerned.

\section{MEDIUM-TERM}

For the purposes of defining "mediumterm" in this paper, it can be considered to have begun at the time when the first definite prediction of an earthquake is made and to end six months before the date on which the quake is predicted.

From overseas experience - and presuming that a major quake does not occur before prediction techniques are perfected - it would appear that a lead time of some years, or at least months, will be given.

Obviously the announcement of the first prediction will in itself be a major news event. It is fair to say that it will lead every front page of every newspaper in New Z̃ealand and lead every television and radio bulletin - possibly for several days.

The type of impact it has on readers, viewers and listeners will to a large extent depend on the type of long-term preparation that has taken place.

It is essential that at the time the prediction is made as much subsidiary information as possible is also made available. This should be in the form of background briefings, papers on any overseas experience which is applicable and specific preparations people can make in light of the impending quake.

It must be expected that the media will make extensive inquiries. How these are met will be crucial as to how the news is presented. It is at this time that the "no comment" or any moves to hide news could be, in my opinion, especially damaging.

Nothing could have a worse effect than for independent news probing to uncover some major fact which has been been revealed in the briefings given by those announcing the prediction.

At this time, those dispensing information must be prepared to counter and correct "sensational" stories. It is almost certain that the minority of people with a vested interest in sensationalising the news will take this opportunity to over-dramatise the situation. We are fortunate in New Zealand, 
however, in having a variety of media - most extremely responsible in their handling of the news - to counter this type of exploitation.

My guesswould be that after the initial high news interest there will be a period when news interest slumps. It is at this time, the authorities will have to decide when they wish to stimulate interest in any specific areas - i.e.: in the construction field, in insurance, in emergency first-aid procedures, etc.

\section{SHORT-TERM}

For the purposes of determining "shortterm" "this can be said to be the time from six months before the predicted earthquake - through to the date of the quake. The American study sponsored by the National Academy of Sciences "Earthquake Prediction and Public Policy" prepared by the Panel on Public Policy Implications of Earthquake Prediction of the Advisory Committee on Emergency Planning in an excellent chapter on "Issuing Warnings and Predictions" makes the careful distinction between predictions and warnings. A prediction, it says, "is a neutral statement that accumulated observations seem to signal more or less clearly the occurrence of an earthquake of a specified magnitude at a specified location and time". A warning, on the other hand, is a "declaration that normal life routines should be altered for a time to deal with a danger impending or at hand". $I^{*}$

The chapter goes on to say, "Predictions are based on science; they involved the detection, measurement and evaluation of changes in the environment that could result in a danger of one sort or another. Warnings, on the other hand, are interpretations of predictions that take public policy into account". 2 *

Obviously by the time any "warning" situation was reached in New Zealand, the central Government could be expected to be heavily involved in policy and planning.

It is interesting to note in the National Academy of Sciences study the parallel drawn between the issuance of earthquake warnings and those for hurricanes and tornadoes. In the case of the latter, there are federal laws in the United States, which exact penalties for broadcaster or telecaster airing false weather reports. There is also, apparently, an unwritten concensus among the public media, which limits the propogation of dissenting or minority reports.

It is almost certain that in New Zealand the Government would take over the task of issuing earthquake warnings in the "countdown" period. There is no doubt that these warnings would receive priority treatment from all sections of the media.

At the same time it would be very surprising if the media in the area - local newspapers and radio stations - were not developing news angles on their own initiative. It is reasonable to assume that these would centre on emergency procedures

I* Earthquake Prediction and Public Policy, National Academy of Sciences $p .47$

2 * Ibid p.47

3* Ibid p. $60-61$ and given the past record of the media, many of these would fall into the category of "public service" features.

A point to consider is planning and prepartion which the media itself may be making in face of the earthquake. If newspaper production plants were in the affected area, for instance, it is certain that the paper's management would be somewhat preoccupied with alternative production plans. But because most companies have well-developed emergency plans, it is also certain that there would be no thought of abandoning full cover of such an important news event.

Radio would be in a different category. It is highly probably that radio would figure as a key element in the Government's emergency planning - especially the publicly-owned Radio New Zealand stations. The ability to manipulate this medium on the part of the authorities would introduce an element of concerted planning which would not be possible with a privately-owned station or privately-owned newspapers - unless special legislation is introduced to cover such a situation.

The same would apply to television. However, it must be remembered that television is the only national medium in New Zealand and presumably any earthquake would only be a local event. One factor which should be considered, however, is that the main headquarters for television in New Zealand are at Avalon and if this fell within the predicted severe earthquake area there would be major problems both preceding and after the earthquake.

\section{INACCURATE PREDICTION}

It is not my intention in this paper to cover the aftermath of any predicted earthquake. One question which must be considered, however, is the effect of a totally inaccurate prediction.

In looking at the effect of inaccurate predictions it is necessary to examine two areas.

On one hand it is accepted that in the early stages of earthquake prediction there will be a number of inaccuracies while techniques are perfected. These inaccuracies could be in either the magnitude, time or location of quakes. How well they are accepted by both the media and the general public will to a large extent depend upon the type of information which precedes them and the success in building an efficient and worthwhile educational programme.

More serious effects will come from an inaccurate prediction which is couched in more definitive terms and which comes on the heels of a number of accurate or partially accurate predictions.

Both the media and the general public will have high expectations in this latter situation and there will be a correspondingly strong reaction to failure. This strong reaction will not only affect immediate events after the quake fails to eventuate but will obviously affect future attitudes. It would seem that some intensive study would be in order to work out some counter 
programme in the field of public education if the obvious benefits of earthquake prediction are not to be totally lost.

\section{SUMMING UP}

In summing up it would seem to me that the main problem which must be tackled immediately is to decide how information on earthquake prediction in New Zealand will be dispensed.

Let us look at the advantages in setting up some satisfactory and effective apparatus.

1. We are a small and highly-centralised nation.

2. Most scientific research is in the hands of one organisation - the Government which means that in a field such as earthquake prediction there would be no competing information (if one discounts that dispensed by crackpot seers and religious fanatics) to divert attention from that which is dispensed officially.

3. New Zealand society is reasonably homogeneous which means that reaction can be judged much more easily to any given event.

4. Along with that homogenety is a phlegmatic side to the New Zealand character which means that an hysterical reaction to something such as earthquake prediction is extremely unlikely.

5. There is a strong sense of community in New Zealand - especially on the news media front. This localisation, coupled with the fact that the population is highly literate, means that it would be comparatively easy to put across any message and be sure of getting an almost blanket coverage.

6. The New Zealand media in general acts in a responsible way and is strongly oriented toward public service journalism. It is certain that almost all newspapers would emphasise this aspect of earthquake prediction, although it must be expected that the dramatic aspects of the story would receive some attention.

In light of these factors, it is my opinion that a highly satisfactory information programme could be put into operation. It will, however, require careful thought and planning on the part of those directly concerned. I would urge, very strongly, that media representatives be involved in the formulation of that programme and that initial moves start as soon as possible.

\section{REFERENCES}

Allen, Clarence J., "Responsibilities in Earthquake Prediction", Bulletin of the Seismological Society of America, December, 1976.

Haas, J. E., and Mileti, D. S., "Consequences of Earthquake Prediction on Other Adjustments to Earthquakes" Paper presented at

Australian Academy of Science Symposium on Natural Hazards in Australia, May 26-29, 1976.

Haas, J. E., and Mileti, D. S., "Socioeconomic Impact of Earthquake Prediction on Government Business and Community" "Institute of Behavioral Science, University of Colorado, Boulder, Colorado.

Hamilton, Robert M. "The Status of Earthquake Prediction", Geological Survey Circular 729.
Panel on Public Policy Implication of Earthquake Prediction of the Advisory Committee on Emergency Planning, Earthquake Prediction and Public Policy, National Academy of Sciences, Washington, D.C., 1975.

\section{DISCUSSION}

After some discussion as to who should be the source of information for the media, Mr. Robson stated that he would prefer the information to come from a panel of scientists so that possible conflict of opinion could be avoided. He also considered that the media could carry out a public eduction programme to get people used to the idea of earthquake predictions and make them aware of the meaning of the terms used in the prediction, i.e. explain the concepts of probabilities and chance. 